\title{
Bcl-2-related protein A1 is an endogenous and cytokine-stimulated mediator of cytoprotection in hyperoxic acute lung injury
}

\author{
Chuan Hua He, ${ }^{1}$ Aaron B. Waxman, ${ }^{2}$ Chun Geun Lee, ${ }^{1}$ Holger Link, ${ }^{3}$ Morgan E. Rabach, ${ }^{1}$ \\ Bing Ma, ${ }^{1}$ Qingsheng Chen, ${ }^{1}$ Zhou Zhu, ${ }^{1}$ Mei Zhong, ${ }^{4}$ Keiko Nakayama, ${ }^{5}$ \\ Keiichi I. Nakayama, ${ }^{6}$ Robert Homer, ${ }^{1}$ and Jack A. Elias' ${ }^{1}$
}

\begin{abstract}
1Department of Internal Medicine, Section of Pulmonary and Critical Care Medicine, Yale University School of Medicine, New Haven, Connecticut, USA. ${ }^{2}$ Pulmonary and Critical Care Unit, Massachusetts General Hospital, Harvard Medical School, Boston, Massachusetts, USA. ${ }^{3}$ Department of Pediatrics, Oregon Health Sciences University, Portland, Oregon, USA. ${ }^{4}$ Department of Internal Medicine, Section of Endocrinology, Yale University School of Medicine, New Haven, Connecticut, USA. ${ }^{5}$ Division of Developmental Genetics, Center for Translational and Advanced Animal Research on Human Diseases, Tohoku University School of Medicine, Sendai, Miyagi, Japan. ${ }^{6}$ Department of Molecular and Cellular Biology, Medical Institute of Bioregulation, Kyushu University, Fukuoka, Fukuoka, Japan.
\end{abstract}

\begin{abstract}
Hyperoxic acute lung injury (HALI) is characterized by a cell death response with features of apoptosis and necrosis that is inhibited by IL-11 and other interventions. We hypothesized that Bfl-1/A1, an antiapoptotic Bcl-2 protein, is a critical regulator of HALI and a mediator of IL-11-induced cytoprotection. To test this, we characterized the expression of A1 and the oxygen susceptibility of WT and IL-11 $\operatorname{Tg}(+)$ mice with normal and null $A 1$ loci. In WT mice, $100 \% \mathrm{O}_{2}$ caused TUNEL ${ }^{+}$cell death, induction and activation of intrinsic and mitochondrial-death pathways, and alveolar protein leak. Bcl-2 and Bcl-xl were also induced as an apparent protective response. A1 was induced in hyperoxia, and in A1-null mice, the toxic effects of hyperoxia were exaggerated, Bcl-2 and Bcl-xl were not induced, and premature death was seen. In contrast, IL-11 stimulated A1, diminished the toxic effects of hyperoxia, stimulated Bcl-2 and Bcl-xl, and enhanced murine survival in $100 \% \mathrm{O}_{2}$. In A1-null mice, IL-11-induced protection, survival advantage, and Bcl-2 and Bcl-xl induction were significantly decreased. VEGF also conferred protection via an A1-dependent mechanism. In vitro hyperoxia also stimulated $\mathrm{A} 1$, and $\mathrm{A} 1$ overexpression inhibited oxidant-induced epithelial cell apoptosis and necrosis. $\mathrm{A1}$ is an important regulator of oxidant-induced lung injury, apoptosis, necrosis, and Bcl-2 and Bcl-xl gene expression and a critical mediator of IL-11- and VEGF-induced cytoprotection.
\end{abstract}

\section{Introduction}

Supplemental oxygen is commonly administered to patients with serious pulmonary or cardiac disorders to increase tissue oxygen delivery. However, very high concentrations of oxygen (fractional concentrations of oxygen greater than 50\%), when administered for a prolonged period, cause hyperoxic acute lung injury (HALI) characterized by endothelial and epithelial injury and enhanced alveolar capillary protein leak (1-6). Early studies of this response led to the free radical theory, which suggests that, in $100 \% \mathrm{O}_{2}$, lung cells poison themselves by producing an excess of $\operatorname{ROS}(3,7)$. Recent studies from our laboratory and others have added to this pathogenetic paradigm by demonstrating that these ROS mediate their effects, in part, by inducing an epithelial and endothelial cell death response with features of apoptosis and necrosis $(3-6,8)$. Surprisingly, the pathways that regulate this cell death response have not been characterized.

Nonstandard abbreviations used: AIF-1, apoptosis-inducing factor- 1 ; BAL, bronchoalveolar lavage; CC10, Clara cell $10 \mathrm{kDa}$; HALI, hyperoxic acute lung injury; hGH, human growth hormone; MLE, murine lung epithelial; rIL-11, recombinant IL-11; $\mathrm{RPA}$, ribonuclease protection assay; rtTA, reverse tetracycline transactivator; $\mathrm{tBid}$, truncated Bid; tet-O, polymeric tetracycline operator.

Conflict of interest: The authors have declared that no conflict of interest exists.

Citation for this article: J. Clin. Invest. 115:1039-1048 (2005).

doi:10.1172/JCI200523004
To define sites at which therapies might be directed to control HALI, interventions have been defined that induce hyperoxic tolerance. In accord with our concepts of disease pathogenesis, early studies demonstrated that IL-1 and TNF induce tolerance and that antioxidants play an important role in these protective responses $(9,10)$. Antioxidants by themselves, however, do not reverse or prevent all of the manifestations of $\operatorname{HALI}(3,11,12)$. In addition, recent studies from our laboratory and others demonstrated that cytokines such as IL-11 and IL-6 confer protection in HALI and that this response is the result of the ability of IL-11 to inhibit hyperoxia-induced cell death without causing major alterations in lung antioxidants $(5,6)$. Little else is known, however, about the mechanism(s) of this protective response.

The many members of the $\mathrm{Bcl}-2$ gene family are key regulators of cell survival, apoptosis, and necrosis $(4,13,14)$. Based on structural and functional properties they can be divided into 3 groups: antiapoptotic $\mathrm{Bcl}-2$-type proteins, proapoptotic Bax-type proteins, and proapoptotic $\mathrm{BH} 3$-domain-only family members $(4,13-15)$. In keeping with the importance of cell death in the pathogenesis of HALI, the regulation and importance of selected Bcl-2 family members in hyperoxic injury has been investigated. These studies highlighted the accumulation of Bax and Bcl-xl mRNA in lungs from mice exposed to $100 \% \mathrm{O}_{2}(3,4,16)$. However, they did not provide a clear picture of the role of these altera- 
A

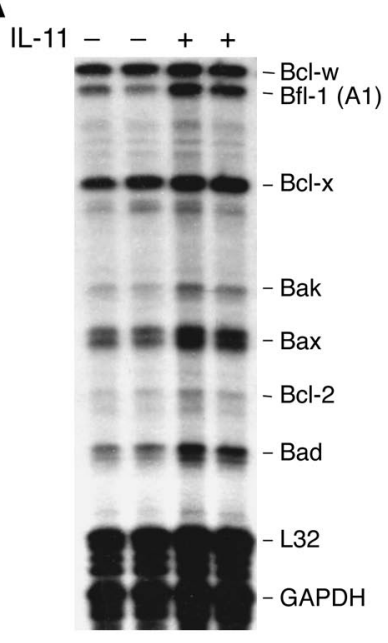

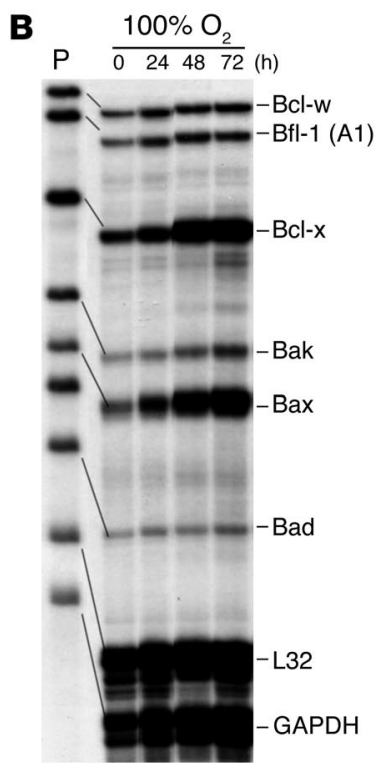

tions in the pathogenesis of HALI and did not adequately assess the roles of other $\mathrm{Bcl}-2$ proteins.

Bfl-1/A1 (hereafter referred to as A1) is an antiapoptotic Bcl-2 family member that is preferentially expressed in hematopoietic and endothelial cells and produced by appropriately stimulated mast, smooth muscle, $T$, and myeloma cells (14, 17-19). In many of these tissues, cytokines such as IL-1, TNF, and IGF-1 stimulate A1 expression (20-22). A1 has protective effects in a variety of settings, including TNF-induced, drug-induced, and growth factor withdrawal-induced apoptosis $(14,19,23-27)$. Surprisingly, its ability to regulate oxidant-induced cell death responses, its importance in the induction of other Bcl-2 family proteins, and its regulatory effects in HALI have not been investigated.

We hypothesized that A1 is a critical regulator of hyperoxiainduced cell death and lung injury and of cytokine-induced cytoprotection in this setting. To test this hypothesis we characterized the regulation of A1 by IL-11, hyperoxia, and VEGF and bred A1null mice with IL-11 dual-construct-positive CC10-rtTA-IL-11 mice [hereafter referred to as $\mathrm{Tg}(+)$ mice] or VEGF $\mathrm{Tg}(+)$ mice to define the roles of A1 in the protective effects of these moieties. These studies demonstrate that IL-11, VEGF, and $100 \% \mathrm{O}_{2}$ stimulate A1. They also demonstrate that, in the absence of A1, the toxic effects of $100 \% \mathrm{O}_{2}$ in $\mathrm{Tg}(-)$ mice are exaggerated, $\mathrm{Bcl}-2$ and $\mathrm{Bcl}-\mathrm{xl}$ are not appropriately induced, and the protective effects of transgenic IL-11 and VEGF are diminished. Lastly, they demonstrate that hyperoxia stimulates epithelial cell A1 and that the overexpression of A1 moieties minimizes oxidant-induced epithelial cell apoptosis and necrosis in vitro.

\section{Figure 2}

Role of A1 in hyperoxia. (A) Two-month-old WT mice (black squares) and IL-11 Tg(+) mice with (+/+) (black circles), (+/-) (gray circles), and $(-/-)$ (white circles) $A 1$ loci were exposed to $100 \% \mathrm{O}_{2}$, and survival was assessed. The noted values represent the survival of a minimum of 8 animals at each time point. ${ }^{\star} P<0.05$; ${ }^{\star *} P<0.01$. (B) Two-monthold $\mathrm{Tg}(-)$ mice with $(+/+)$ (black squares), (+/-) (gray squares), and $(-/-)$ (white squares) $A 1$ loci were exposed to $100 \% \mathrm{O}_{2}$, and survival was assessed. The noted values represent the survival of a minimum of 8 animals at each time point. ${ }^{*} P<0.05 ;{ }^{* *} P<0.01$.

\section{Figure 1}

Regulation of $\mathrm{A} 1$ by IL-11 and $100 \% \mathrm{O}_{2}$. (A) RPA was used to assess the levels of mRNA encoding $A 1$ and related proteins in whole-lung mRNA from 2-month-old $\mathrm{Tg}(-)$ and CC10-IL-11 Tg(+) mice. (B) RPA was used to assess the levels of mRNA encoding $A 1$ and related proteins in lungs from WT mice exposed to $100 \% \mathrm{O}_{2}$ for the noted intervals (hours). The noted experiments are representative of a minimum of 4 similar evaluations. $P$, multiprobe template.

\section{Results}

Regulation of $A 1$ expression by transgenic IL-11 and hyperoxia. To begin to understand the biologic roles of A1, studies were undertaken to define the expression of A1 in lungs from WT mice, IL-11 $\mathrm{Tg}(+)$ mice, and WT mice exposed to $100 \% \mathrm{O}_{2}$. A1 mRNA was readily detected in lungs from WT $\mathrm{Tg}(-)$ littermate control mice (Figure 1). As seen in Figure $1 \mathrm{~A}, \mathrm{IL}-11$ caused a significant increase in $\mathrm{A} 1$ mRNA accumulation. This A1-inductive effect was seen in all animals between 1 and 3 months of age (Figure 1 and data not shown). It was also partially A1-specific, since Bcl-w and Bcl-x were not similarly regulated while Bak, Bax, and Bcl-2 were induced in this setting. Interestingly, it was not IL-11-specific, since hyperoxia was also a potent inducer of A1 mRNA accumulation (Figure 1B). In all cases, restriction digestion demonstrated induction of $\mathrm{A} 1 \mathrm{a}$, and lesser amounts of A1b and A1d (data not shown).

Role of A1 in IL-11-induced cytoprotection. To define the role(s) of A1 in the protective effects of IL-11, IL-11 $\mathrm{Tg}(+)$ mice were bred with mice with a null $(-/-)$ mutation of $A 1$, and the survival in $100 \% \mathrm{O}_{2}$ of IL- $11 \mathrm{Tg}(+)$ mice with (+/+), (+/-), and (-/-) A1 loci was compared. In accord with our prior report (6), IL-11 $\mathrm{Tg}(+)$ mice with $(+/+)$ A1 loci manifest impressive survival in $100 \% \mathrm{O}_{2}$ compared with $\operatorname{Tg}(-)$ littermate controls (Figure 2A). In these experiments, $\mathrm{Tg}(-)$ mice died after $4-6$ days of $100 \% \mathrm{O}_{2}$ exposure, while IL-11(+)/A1(+/+) mice died after 9-14 days of $100 \% \mathrm{O}_{2}$ exposure $(P<0.001)$. This protective effect was, to a great extent, A1-dependent. This was most impressive in IL-11(+)/A1(-/-) mice that
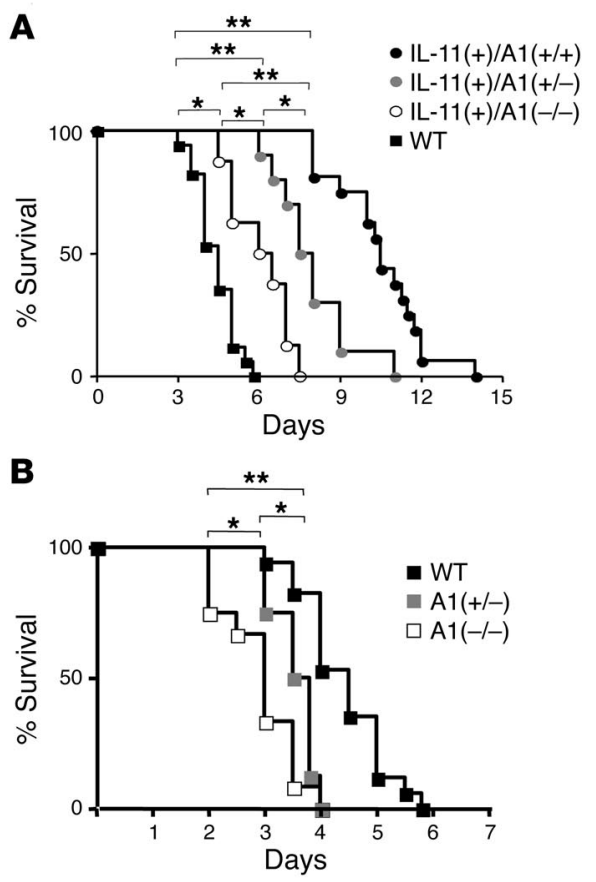


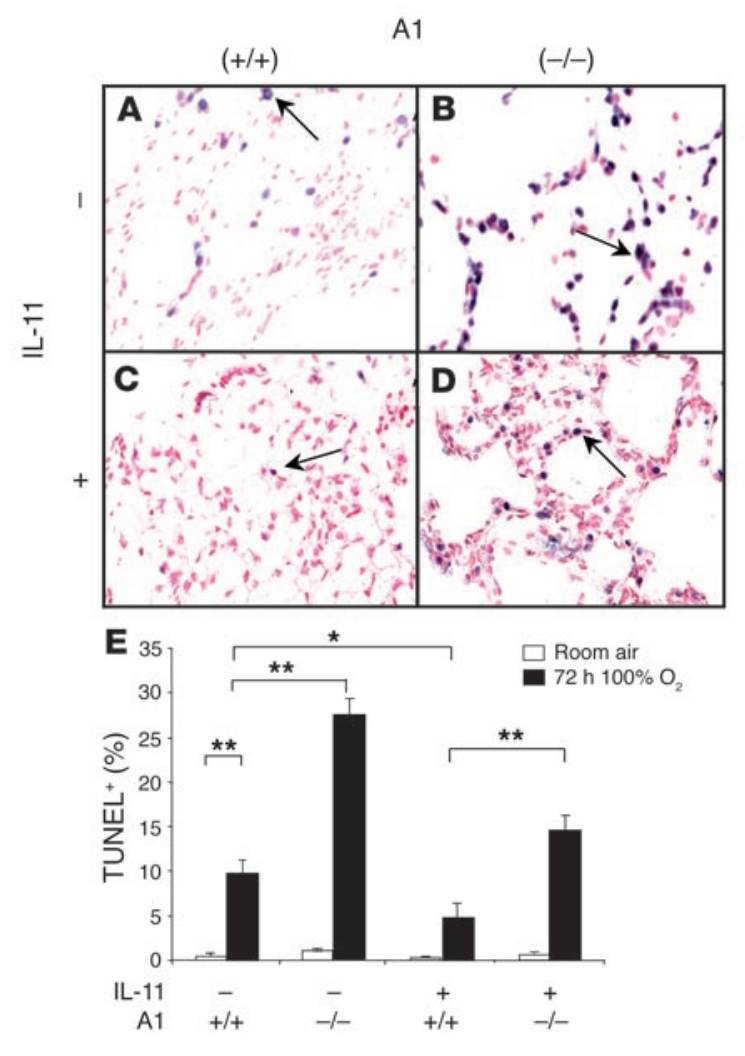

died after 6-7 days of $100 \% \mathrm{O}_{2}$ exposure $(P<0.01$ versus IL-11 $[+] /$ $\mathrm{A} 1[+/+])$ (Figure 2A). Interestingly, IL-11 $\mathrm{Tg}(+)$ mice with (+/-) A1 loci had an intermediate phenotype, dying after $7-11.5$ days of $100 \% \mathrm{O}_{2}$ exposure $(P<0.05$ versus IL- $11 \mathrm{Tg}[+]$ mice with $[+/+]$ and $[-/-]$ loci) (Figure 2A). These studies demonstrate that A1 plays a critical role in IL-11-induced cytoprotection in HALI.

Role of A1 in HALI. The studies noted above demonstrate that A1 has impressive protective effects in HALI. Because A1 is induced in lungs from WT mice in $100 \% \mathrm{O}_{2}$, we hypothesized that this induction contributes to the rate of progression and severity of the lung injury induced in this setting. To test this hypothesis, we compared the survival in $100 \% \mathrm{O}_{2}$ of WT, $A 1(+/-)$, and $A 1(-/-)$ animals. As noted above, WT mice died after 4-6 days of hyperoxia (Figure $2 \mathrm{~B}$ ). In the absence of $\mathrm{A} 1$ the toxic effects of $100 \% \mathrm{O}_{2}$ were more pronounced, with $A 1(-/-)$ mice dying after $2-4$ days of $100 \%$ $\mathrm{O}_{2}$ exposure $(P<0.01$ versus WT mice) (Figure $2 \mathrm{~B})$. A1(+/-) mice had an intermediate phenotype, dying after 3-4 days of $100 \% \mathrm{O}_{2}$ exposure $(P<0.05$ versus WT and $A 1[+/-]$ animals) (Figure $2 \mathrm{~B}$ ). These studies demonstrate that the induction of A1 that occurs during HALI in WT mice is a protective response that feeds back to minimize lung injury.

Effect(s) of A1 on alveolar capillary protein leak. HALI is associated with impressive increases in alveolar-capillary permeability and alveolar protein leak. Studies were thus undertaken to determine whether A1 regulated this response. Exposure to $100 \% \mathrm{O}_{2}$ for 72 hours caused an impressive increase in bronchoalveolar lavage (BAL) protein accumulation in WT mice (BAL protein concentrations $244 \pm 20$ versus $582 \pm 15 \mu \mathrm{g} / \mathrm{ml} ; P<0.01)$. In accord with prior reports (6), IL-11 caused an impressive decrease in this pathologic response $(582 \pm 15$ versus $415 \pm 18 \mu \mathrm{g} / \mathrm{ml} ; P<0.005$, comparing hyperoxia-exposed WT mice with IL-11 $\mathrm{Tg}[+]$ mice). In accord with

\section{Figure 3}

Role of $\mathrm{A} 1$ in hyperoxia-induced TUNEL ${ }^{+}$cell death and DNA injury. $\mathrm{Tg}(-)$ and $\mathrm{Tg}(+)$ mice with (+/+) and (-/-) A1 loci were exposed for 72 hours to room air (white bars) or $100 \% \mathrm{O}_{2}$ (black bars), and TUNEL evaluations were undertaken. The TUNEL evaluations in A-D are representative of a minimum of 9 similar evaluations. The arrows highlight representative TUNEL+ cells. The values in $\mathbf{E}$ are the mean \pm SEM of evaluations in a minimum of 9 mice. ${ }^{\star} P<0.05$; ${ }^{\star \star} P<0.01$.

our demonstration that $\mathrm{A} 1$ limits the toxic effects of $100 \% \mathrm{O}_{2}$, alveolar capillary protein leak was markedly increased in comparisons of $A 1(-/-)$ versus $A 1(+/+)$ mice $(722 \pm 33$ versus $582 \pm 15 \mu \mathrm{g} / \mathrm{ml}$; $P<0.01)$ and comparisons of IL-11 $\mathrm{Tg}(+)$ mice with null mutant versus (+/+) $A 1$ loci $(415 \pm 18$ versus $592 \pm 38 \mu \mathrm{g} / \mathrm{ml} ; P<0.01)$. Thus, endogenous and IL-11-induced A1 is an important inhibitor of $100 \% \mathrm{O}_{2}$-induced alveolar capillary protein leak.

Effect(s) of A1 on TUNEL $L^{+}$cell death. Previous studies from our laboratory and others demonstrated that HALI is associated with a TUNEL ${ }^{+}$cell death response (4-6). Studies were thus undertaken to determine whether A1 regulated this response. In room air, less than $2 \%$ of the cells in lungs from WT and IL-11 $\mathrm{Tg}(+)$ mice with (+/+) and (-/-) A1 loci were TUNEL stain-positive (data not shown). As shown in Figure 3, exposure to $100 \% \mathrm{O}_{2}$ for 72 hours caused an impressive increase in lung-tissue TUNEL staining $(P<0.01)$, and, in accord with prior reports $(6)$, IL-11 inhibited this pathologic response $(P<0.05$ comparing WT mice with IL-11 $\mathrm{Tg}[+]$ mice in hyperoxia). In accord with our demonstration that A1 limits the toxic effects of $100 \% \mathrm{O}_{2}$, TUNEL staining was markedly increased in comparisons of $A 1(-/-)$ versus $A 1(+/+)$ mice and comparisons of IL-11 $\mathrm{Tg}(+)$ mice with $(-/-)$ versus (+/+) A1 loci $(P<0.01$ for all comparisons) (Figure 3$)$. Thus, endogenous $\mathrm{A} 1$ and IL-11-induced A1 are potent inhibitors of $100 \% \mathrm{O}_{2}$-induced cell death and DNA injury.

Effect of A1 on pulmonary caspases. Because caspases play critical roles in apoptosis and necrosis $(13,15)$, we next compared the levels of activation and expression of caspases in lungs from $\operatorname{Tg}(-)$ and $\mathrm{Tg}(+)$ mice with $(+/+)$ and (-/-) A1 loci exposed to room air or $100 \% \mathrm{O}_{2}$ for 72 hours. Exposure to $100 \% \mathrm{O}_{2}$ increased the levels of mRNA encoding caspase- $3,-8$, and -9 and, in this setting, transgenic IL-11 abrogated this increase (Figure 4A). Similarly, hyperoxia increased and transgenic IL-11 inhibited caspase-3, -8, and -9 bioactivity (Figure 4B) and caspase- 3 and -9 activation (Figure 4C). In accord with the demonstration that $\mathrm{A} 1$ limits the toxic effects of $100 \% \mathrm{O}_{2}$, caspase expression, bioactivity, and activation were increased in comparisons of $A 1(-/-)$ versus $A 1(+/+)$ mice and comparisons of IL-11 $\mathrm{Tg}(+)$ mice with $(-/-)$ versus $(+/+)$ A1 loci (Figure $4, \mathrm{~A}-\mathrm{C})$. Thus, $\mathrm{A} 1$ is an important inhibitor of hyperoxia-induced caspase accumulation and activation.

Effect of A1 on cell death regulators. To further define the mechanism(s) by which A1 regulates cell death, we characterized the levels of expression of key mediators of apoptosis and/or necrosis in lungs from $\operatorname{Tg}(-)$ and $\operatorname{Tg}(+)$ mice with $(+/+)$ and (-/-) A1 loci exposed to room air or $100 \% \mathrm{O}_{2}$ for 72 hours. In WT mice, exposure to $100 \% \mathrm{O}_{2}$ increased the levels of Fas, FasL, Bid, Bad, and Bak and increased Bid activation to truncated Bid (tBid) (Figure 5). Similarly, hyperoxia increased the levels of mRNA encoding key pro-cell death moieties including TRAIL, Fas, apoptosis-inducing factor-1 (AIF-1), PKCס, Bid, Bim, and Bak (see Supplemental Figures 1 and 2; supplemental material available online with this article; doi:10.1172/JCI200523004DS1). In hyperoxia, Bcl-2 and 
A
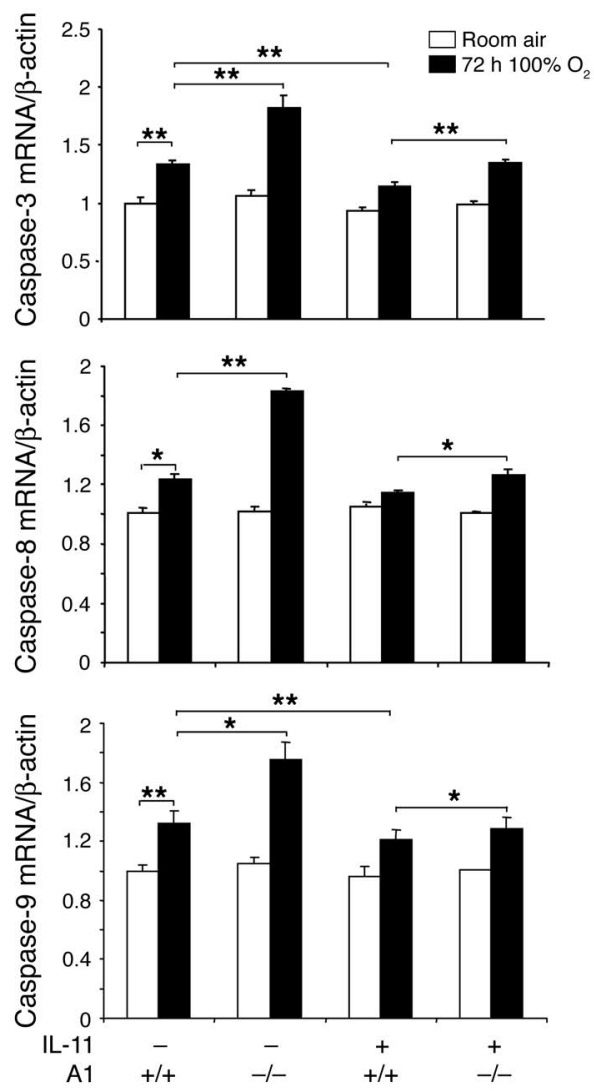

B
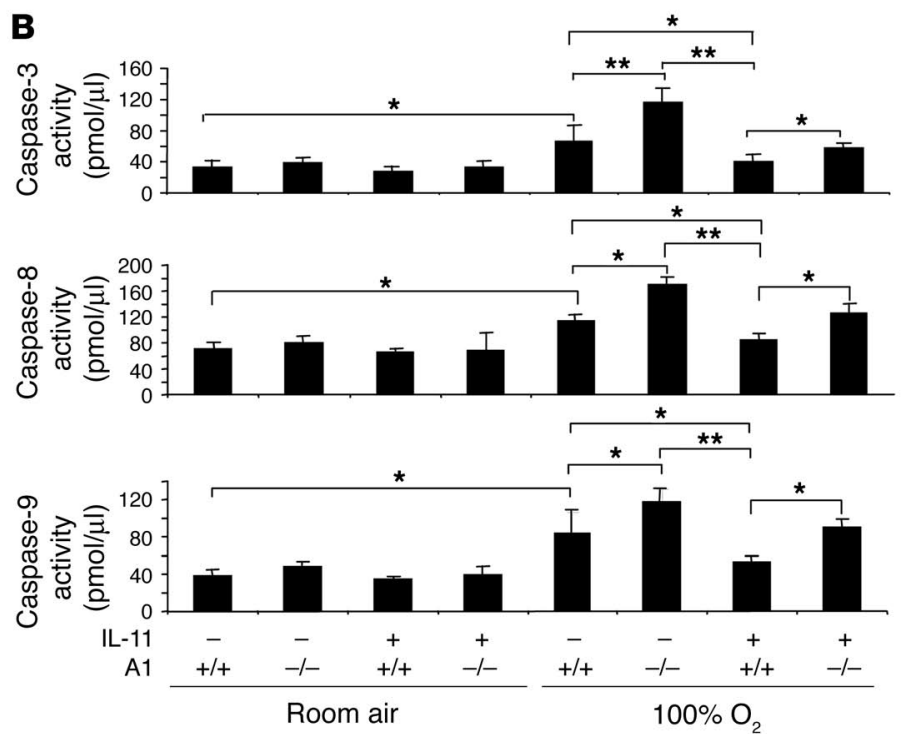

C

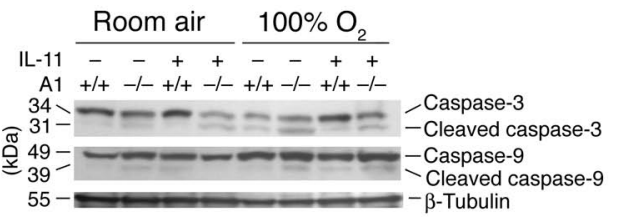

Figure 4

Effects of $\mathrm{A} 1$ on pulmonary caspases. $\mathrm{Tg}(-)$ and $\mathrm{Tg}(+)$ mice with $(+/+)$ and $(-/-) A 1$ loci were incubated in room air or $100 \% \mathrm{O}_{2}$ for 72 hours. The levels of caspase mRNA (real-time RT-PCR) (A), caspase bioactivity (B), and caspase protein (Western blot) (C) were assessed. The values in $\mathbf{A}$ and $\mathbf{B}$ represent the mean \pm SEM of evaluations in a minimum of 5 mice. $\mathbf{C}$ is representative of a minimum of 4 similar evaluations. ${ }^{\star} P<0.05$; ${ }^{\star \star} P<0.01$.

Bcl-xl were also induced as an apparent protective response (Figure 5; Supplemental Figures 1 and 2). In this setting, IL-11 inhibited the accumulation of Fas, FasL, Bid, tBid, Bad, Bax, and Bak (Figure 5). Similarly, IL-11 inhibited the hyperoxia-induced stimulation of the levels of mRNA encoding TRAIL, Fas, AIF-1, PKCס, Bid, Bim, and Bak (Supplemental Figures 1 and 2). IL-11 also stimulated the expression of $\mathrm{Bcl}-2$, and to a lesser extent $\mathrm{Bcl}-\mathrm{xl}$, in room air and interacted with $100 \% \mathrm{O}_{2}$ to further increase the induction of these moieties in hyperoxia (Figure 5; Supplemental Figures 1 and 2). In accord with the demonstration that A1 limits the toxic effects of $100 \% \mathrm{O}_{2}$, the levels of Fas, FasL, Bid, tBid, Bad, Bax, and Bak (Figure 5) and the levels of mRNA encoding FasL, AIF-1, PKCd, Bim, and Bak (Supplemental Figures 1 and 2 ) were increased in comparisons of $A 1(-/-)$ versus $A 1(+/+)$ mice. In addition, the levels of Fas, FasL, Bid, tBid, Bad, Bax, and Bak (Figure 5) and the expression of TRAIL, Fas, FasL, AIF-1, PKCס, Bid, Bim, and Bak were increased in comparisons of IL-11 $\mathrm{Tg}(+)$ mice with $(-/-)$ versus $(+/+)$ A1 loci (Supplemental Figures 1 and 2 ). Interestingly, the ability of hyperoxia and IL-11 to stimulate Bcl-2 and Bcl-xl was also significantly decreased in the absence of A1 (Figure 5; Supplemental Figures 1 and 2). These studies demonstrate that hyperoxia induces and activates key stimulators of the death receptor and mitochondrial cell death pathways and that A1 is an important inhibitor of these responses. They also demonstrate that hyperoxia and IL-11 stimulate $\mathrm{Bcl}-2$ and $\mathrm{Bcl}-\mathrm{xl}$ via A1-dependent mechanisms.
Regulation of $A 1$ by $100 \% \mathrm{O}_{2}$ and $I L-11$ in vitro. Studies were next undertaken to determine whether hyperoxia or IL-11 stimulated the expression of A1 in vitro. In these experiments Northern and Western blot evaluations were used to define the expression and production of A1 in murine lung epithelial (MLE) cells cultured in the presence or absence of $95 \% \mathrm{O}_{2}$ or recombinant IL-11 (rIL-11). In accord with our in vivo findings, A1 was induced by hyperoxia in vitro. Increases in A1 mRNA could be seen after as little as 30 minutes of hyperoxia and persisted throughout the 72-hour study interval (Figure 6A). Increases in A1 protein were noted after as little as 8 hours and were even more apparent after 24 hours of $100 \%$ $\mathrm{O}_{2}$ exposure (Figure 6B). Similar increases in A1 mRNA (Figure $6 \mathrm{C}$ ) and protein (Figure 6D) were induced by rIL-11. Thus, hyperoxia and IL-11 are potent stimulators of epithelial cell A1 in vitro. A1 regulation of apoptosis and necrosis in vitro. To further define the relationship between $\mathrm{A} 1$ and oxidant-induced cell death, FACS (BD Biosciences) analysis was used to define the effects of $100 \%$ $\mathrm{O}_{2}$ on MLE cells in culture. In these experiments we compared WT MLE cells and cells that had been transfected with A1a, A1d, or their vector controls. As seen in Figure 7A, 95\% $\mathrm{O}_{2}$ increased the number of MLE cells undergoing pure apoptosis (lower right quadrant of each panel) or necrosis (upper left quadrant of each panel). It also increased the number of cells with features of both responses (upper right quadrant of each panel). When compared with cells that were not transfected and cells that were transfected 


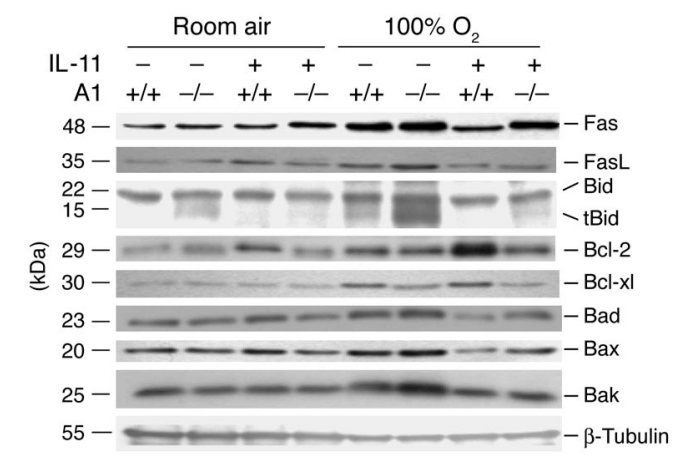

\section{Figure 5}

Effects of $A 1$ on cell death regulators. $\mathrm{Tg}(-)$ and $\mathrm{Tg}(+)$ mice with $(+/+)$ and $(-/-) A 1$ loci were incubated in room air or $100 \% \mathrm{O}_{2}$ for 72 hours. The noted moieties were evaluated by Western blot. Each panel is representative of a minimum of 4 similar evaluations.

with the control vector, cells stably transfected with A1a or A1d showed a significant decrease in hyperoxia-induced apoptotic, necrotic, and mixed death responses (Figure 7A). In accord with our in vivo data, hyperoxia-induced cell death was associated with increased caspase- $3,-8$, and -9 activities, which were also inhibited by $\mathrm{A} 1$ expression (Figure $7 \mathrm{~B}$ ). A1a and A1d also inhibited $\mathrm{H}_{2} \mathrm{O}_{2}$ induced apoptosis and necrosis in a similar manner (data not shown). When viewed in combination, these studies demonstrate that $\mathrm{A} 1$ proteins are potent inhibitors of oxidant-induced lung epithelial cell apoptosis and necrosis in vitro.

Role of A1 in VEGF-induced cytoprotection. Studies were next undertaken to determine whether the protective effects of A1 are specific for IL-11. Because previous studies from our laboratory demonstrated that VEGF also confers cytoprotection in HALI (28), studies were undertaken to determine whether A1 plays a role in this response. We first determined whether VEGF stimulated A1 by comparing the levels of A1 mRNA in lungs from WT and VEGF $\operatorname{Tg}(+)$ mice. As shown in Figure 8, A and B, the transgenic overexpression of VEGF 165 enhanced the levels of A1 mRNA and protein. This stimulatory effect was seen when VEGF was produced for as little as 1 week and persisted throughout the 3-month study interval (Figure 8 and data not shown). VEGF $\mathrm{Tg}(+)$ mice were then bred with $A 1(-/-)$ mice, and the survival in $100 \% \mathrm{O}_{2}$ of VEGF $\mathrm{Tg}(+)$ mice with $(+/+)$ and (-/-) A1 loci was evaluated. When compared with $\mathrm{Tg}(-)$ littermate controls, VEGF $\mathrm{Tg}(+)$ mice demonstrated a remarkable resistance to the toxic effects of $100 \% \mathrm{O}_{2}$ (Figure $8 \mathrm{C}$ ). This protection was significantly decreased in VEGF $\mathrm{Tg}(+)$ mice with null $A 1$ loci (Figure 8C). Thus, VEGF, like IL-11, stimulates A1 and confers cytoprotection in HALI via a mechanism that is at least partially A1-dependent.

\section{Discussion}

To further understand the pathogenesis of oxidant-induced lung injury syndromes, studies were undertaken to define the pathways that regulate the toxic respiratory effects of supraphysiologic concentrations of oxygen. These studies demonstrate that A1 is induced in lungs from WT mice during hyperoxia, where it feeds back to control the severity of this pathologic pulmonary response. They also demonstrate that A1 is induced by IL-11 and VEGF and that this induction is a key event in the pathogenesis of the cytoprotective effects that these cytokines have in HALI. Mechanistic insights were also obtained, since these studies demonstrate that the protective effects of $\mathrm{A} 1$ are associated with decreased hyperoxia-induced induction and activation of key caspases and components of the extrinsic/death receptor and intrinsic/mitochondrial cell death pathways, and with the A1-dependent induction of the antiapoptosis proteins Bcl-2 and Bcl-xl. Lastly, they demonstrate that A1 is induced by hyperoxia and IL-11 in vitro and that the overexpression of A1 inhibits the oxidant-induced necrosis and apoptosis of epithelial cells in culture. When viewed in combination, these studies demonstrate that A1 is an endogenous and cytokine-induced cytoprotective molecule that plays a critical role in the regulation of the apoptotic and necrotic responses that are induced by hyperoxia in the lung.

The ability of $100 \% \mathrm{O}_{2}$ to cause acute lung injury with endothelial and epithelial cell injury, noncardiac pulmonary edema, and eventually death is well documented in rodent and other modeling systems $(2,4-6,16,29)$. For reasons that are not clear, however, inbred mice can survive for as little as 3 days or as long as 6 days in $100 \% \mathrm{O}_{2}(5,6,30)$. The mechanisms that account for the delay in the appearance of HALI and for the noted animal-to-animal variation are poorly understood. This lack of understanding may be the result of an inadequate appreciation of the factors that control oxidant-induced injury in the lung. The present studies and studies from our laboratory and others $(2,3,5,6)$ demonstrate that $100 \% \mathrm{O}_{2}$ causes a TUNEL ${ }^{+}$cell death response with features of apoptosis and necrosis in vivo. They also address the complex nature of this cell death response by demonstrating that hyperoxia can induce apoptosis, necrosis, or a mixture of the 2 in vitro $(2,3$, $15,31)$. Importantly, A1 was a potent inhibitor of all of these in vivo and in vitro responses. The demonstration that A1 is a critical regulator of pulmonary apoptosis is in accord with prior studies that demonstrate that A1 inhibits the apoptosis induced by a variety of stimuli in a variety of cells and tissues $(14,18-20,32)$. In contrast, to our knowledge, these are the first studies to demon-

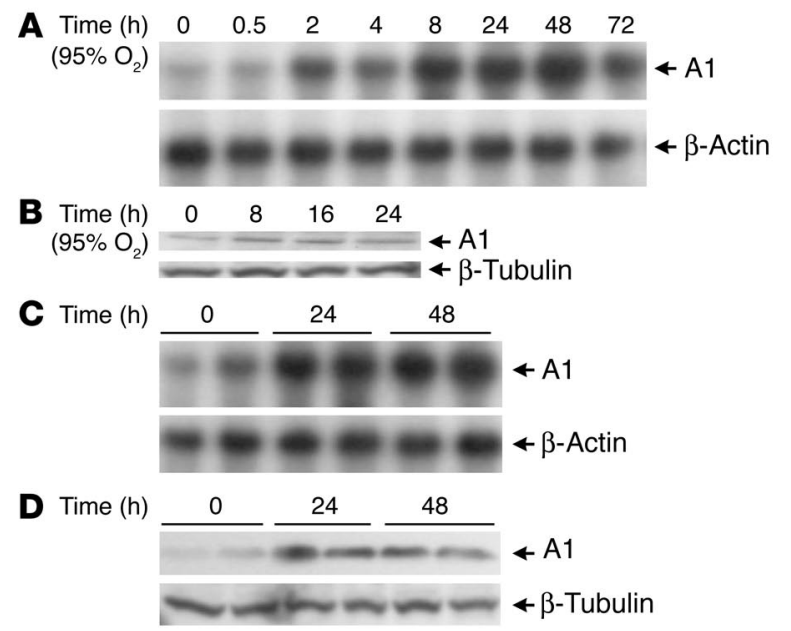

\section{Figure 6}

Effects of hyperoxia and rIL-11 on epithelial cell A1 in vitro. MLE cells were incubated under normoxic or hyperoxic $\left(95 \% \mathrm{O}_{2}\right)$ conditions $(\mathbf{A}$ and $\mathbf{B})$ or in the presence or absence of $\mathrm{rlL}-11(25 \mathrm{ng} / \mathrm{ml})(\mathbf{C}$ and $\mathbf{D})$ for the noted periods of time, and the levels of mRNA encoding A1 ( $A$ and $\mathbf{C}$ ) and the levels of $\mathbf{A} 1$ protein ( $\mathbf{B}$ and $\mathbf{D}$ ) were assessed by Northern and Western blot, respectively. The panels are representative of a minimum of 4 similar evaluations. 
A

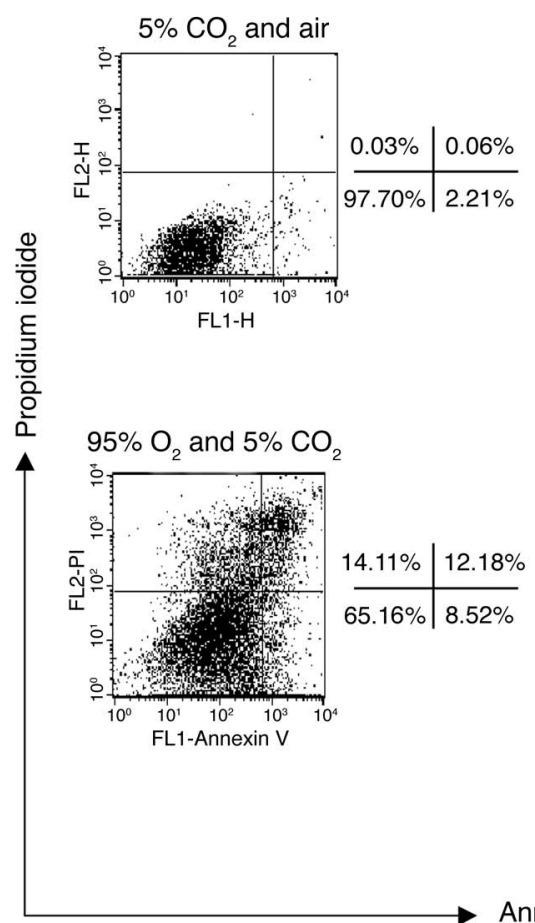

pcDNA3.1

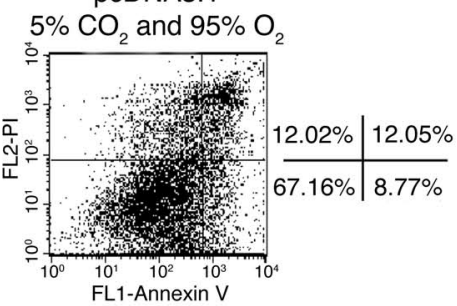

A1a-pcDNA3.1
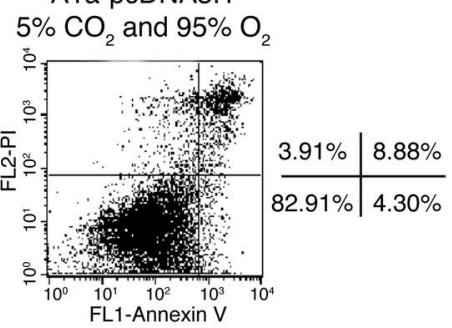

A1d-pcDNA3.1 $5 \% \mathrm{CO}_{2}$ and $95 \% \mathrm{O}_{2}$

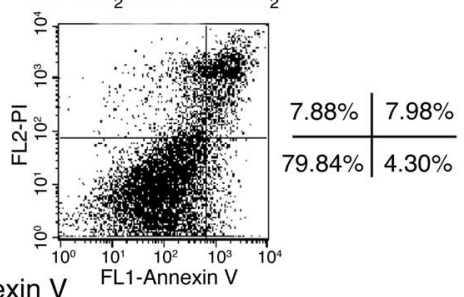

B
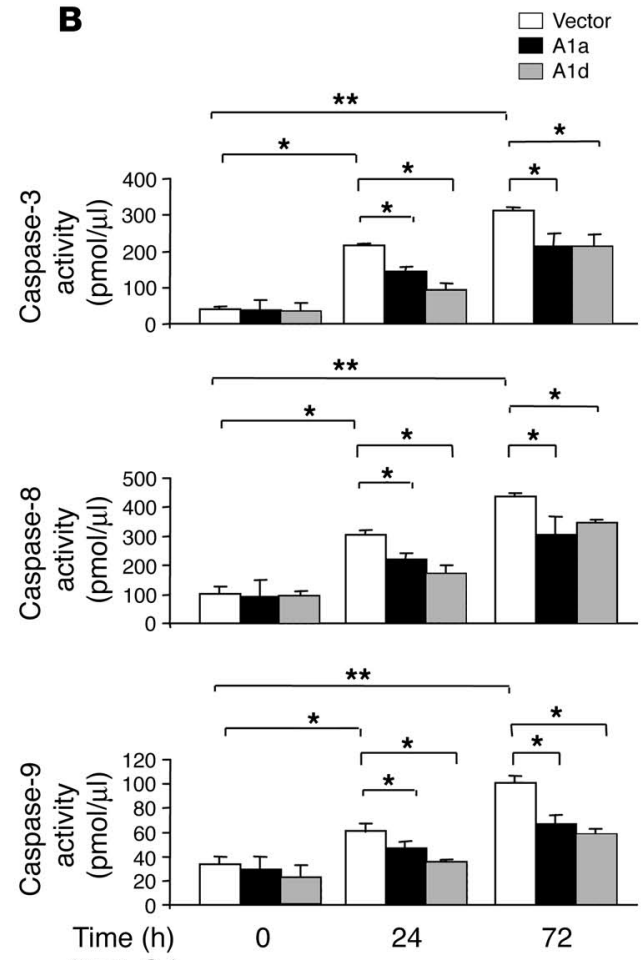

$\left(95 \% \mathrm{O}_{2}\right)$

Figure 7

A1 regulation of hyperoxia-induced apoptosis and necrosis in vitro. MLE cells were stably transfected with an expression construct alone (pcDNA3.1) (vector) or the same construct containing cDNA encoding A1a (A1a-pcDNA3.1) or A1d (A1d-pcDNA3.1). The cells were incubated under normal conditions $\left(5 \% \mathrm{CO}_{2}\right.$ and air) or under hyperoxic conditions $\left(95 \% \mathrm{O}_{2}\right.$ and $\left.5 \% \mathrm{CO}_{2}\right)$. (A) Annexin $\mathrm{V}$ and propidium iodide (PI) staining are analyzed with FACS to compare the apoptosis and necrosis induced by 72 hours in $95 \% \mathrm{O}_{2}$. (B) We compare the caspase activities in these cells before (0 hours) and at intervals after the start of $95 \% \mathrm{O}_{2}$ exposure. The FACS diagrams are representative of a minimum of 4 similar evaluations. The values in $\mathrm{B}$ are the mean $\pm \mathrm{SEM}$ of evaluations in a minimum of 5 mice. ${ }^{*} P<0.05 ;{ }^{* *} P<0.01$.

strate that $\mathrm{A} 1$ is an important regulator of oxidant-induced necrosis. These findings are not without precedent, however, because it has recently been appreciated that pathways that were previously thought to be unique to apoptosis (caspase- 8 and Bid activation) also play key roles in cellular necrosis (15).

IL-11 is a multifunctional IL-6-type cytokine that is produced by epithelial cells, fibroblasts, eosinophils, and other cells in response to a number of stimuli, including IL- $1, \mathrm{TGF}-\beta_{1}$, and respiratory virus $(33,34)$. Early studies of IL-11 focused on its stimulatory roles in megakaryocytopoiesis and thrombopoiesis and its ability to activate osteoclasts and induce bone resorption. It has subsequently been appreciated that IL-11 has remarkable mucosal protective effects in the setting of chemotherapy and radiation therapy that may result from its ability to inhibit macrophage production of IL-1, TNF, and IL-12 and inhibit the activation of NF-KB (33-39). Previous studies from our laboratory demonstrated that IL-11 also confers cytoprotection in HALI (6). This protective effect could not be accounted for by antioxidant alterations. Instead, IL-11 appeared to be a potent inhibitor of the hyperoxiainduced cell death response (6). The present studies add to our knowledge of the mechanism of this protective response by demonstrating that A1 is a critical mediator of this cytoprotection. They also demonstrate that this protective response is not IL-11-specific, since VEGF, a known regulator of apoptosis (22, 40-42), also conferred cytoprotection via a mechanism that is, at least partially, A1dependent. Transgenic GM-CSF has recently been shown to confer protection in HALI (30). It is tempting to speculate that A1 contributes to this response as well, because A1 was originally described by Prystowsky and colleagues as a gene in bone marrow that was potently stimulated by GM-CSF (43). In combination, these observations suggest that $\mathrm{A} 1$ induction is a commonly employed pathway that cytokines and, potentially, other stimuli use to control oxidant-induced injuries. It is important to point out, however, that A1-independent pathways also appear to be operative, since IL-11 and VEGF transgenic mice with null mutations of $A 1$ still lived for an extended interval in $100 \% \mathrm{O}_{2}$ when compared with WT controls. Additional experimentation will be required to define the A1-independent mechanisms that are operative in this setting.

Under physiologic conditions, tissue homeostasis is preserved by the tight control of apoptosis and necrosis. This is accomplished by the continuous integration of pro- and anti-cell death signals (44). Although cell death can be triggered by a vast array of stimuli and mediated via an increasingly complex series of pathways, the vast majority of signals engage the cell death machinery at the level of the cell membrane or at the level of the mitochondria. The membrane ("extrinsic") pathway triggers surface "death receptors" 
A

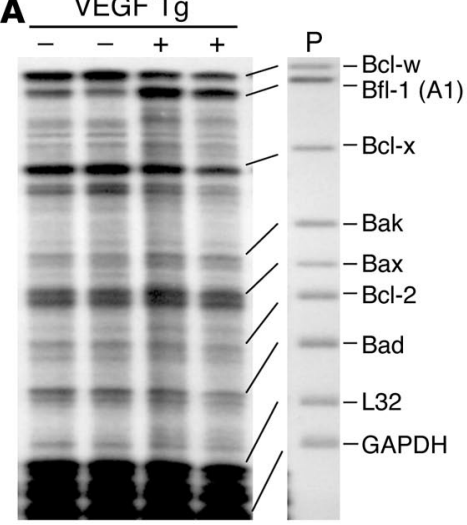

B

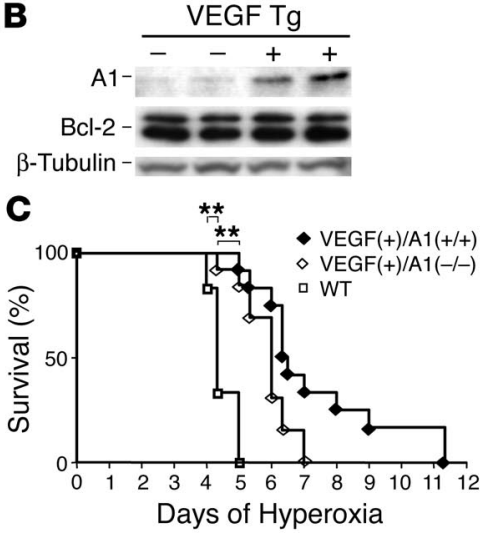

\section{Figure 8}

Induction of A1 and its role in VEGF cytoprotection. Lungs were obtained from $\mathrm{Tg}(-)$ and VEGF $\mathrm{Tg}(+)$ mice on doxycycline water for 1 month. (A) A1 mRNA was quantitated by RPA. (B) A1 protein was evaluated by Western blot analysis. (C) The survival of $\mathrm{Tg}(-)$ mice (open squares) and VEGF $\mathrm{Tg}(+)$ mice with (+/+) (filled diamonds) and (-/-) (open diamonds) $A 1$ loci in $100 \% \mathrm{O}_{2}$. A and $\mathbf{B}$ are representative of a minimum of 4 similar evaluations. The values in $\mathbf{C}$ illustrate the survival of a minimum of 6 mice at each time point. $P$, multiprobe template. ${ }^{\star \star} P<0.05$. such as Fas, which binds FasL, and TNF receptor I, which binds TNF and lymphotoxin, and it activates caspase-8. Other stimuli use mitochondrial dysfunction to signal death responses. In this "intrinsic" response, $\mathrm{BH} 3$-domain-only family members such as Bid are activated to $\mathrm{tBid}$ and interact with Bax-type proteins (Bax, Bak, Bok) to form or interact with mitochondrial pores, release cytochrome $c$, activate caspase-9, and induce cell death $(13,14,44)$. Fas system alterations and mitochondria-dependent cell death pathway activation have been noted in hyperoxia $(15,31)$. Thus, to further understand the mechanism(s) of hyperoxia-induced cell death and the effects of A1, we characterized major features of the intrinsic and extrinsic pathways in mice with WT and null $A 1$ loci. These studies demonstrate that hyperoxia induces and activates caspase- $3,-8$, and -9 and key components in the extrinsic/death receptor and intrinsic/mitochondrial cell death pathways. They also demonstrate that $\mathrm{A} 1$ inhibits the caspase, death receptor, and mitochondrial activation events that were seen. Interestingly, they also demonstrate that hyperoxia and IL-11 induce the prototypic antiapoptotic proteins $\mathrm{Bcl}-2$ and $\mathrm{Bcl}-\mathrm{xl}$, and that these inductive events are mediated via an A1-dependent pathway. It is not possible, in these complex whole-lung systems, to define the critical sites of A1 production or the relative importance of each of its many effects on the cell death machinery. However, when these studies are combined with prior studies in lymphocytes and other systems that demonstrate that A1 can inhibit Bid cleavage, sequester $\mathrm{tBid}$, and inhibit the activation of caspase- 3 and $-8(14,25,45)$, it is clear that endogenous A1 is a multifunctional regulator of oxidant-induced apoptotic and necrotic responses in the lung. These studies also demonstrate an additional level of complexity in the Bcl-2 gene family. Specifically, in addition to differences in their function and cytokine inducibility and their need to form homoand heterodimers to mediate their effects $(14,19,46)$, they interact with one another in a Bcl-2 gene cascade that plays an important role in their stimulation at sites of tissue injury.

Oxidative injury is a key element in the pathogenesis of a wide variety of diseases and disorders. This is nicely illustrated in the lung, where hyperoxia leads to acute and chronic injuries such as bronchopulmonary dysplasia in the newborn and adult respiratory distress syndrome in adults. Oxidant injury also plays a major role in the pathogenesis of interstitial lung diseases, asthma, and chronic obstructive pulmonary disease and can worsen the pathologic effects of pulmonary infections (29, 47-49). Our studies demonstrate, for the first time to our knowledge, that $\mathrm{A} 1$ is induced by hyperoxia and by protective cytokines and that, after this induction, it is a key endogenous regulator of oxidative injury in the lung. They also highlight the multifaceted mechanism of the protection conferred by A1, with impressive inhibitory effects on caspases and the extrinsic/death receptor and intrinsic/mitochondrial cell death pathways. These observations have a number of important implications. First, they suggest that therapies that increase the expression and/or effector functions of A1 can be therapeutically useful in the treatment of these diseases. They also suggest that genetic polymorphisms or environmental exposures that alter the production or effector functions of A1 can have major effects on an individual's ability to tolerate an oxidative load and thus could contribute to the patient variability that is seen in the severity and natural history of these disorders.

\section{Methods}

IL-11 transgenic mice. In these experiments we used transgenic mice that were generated in our laboratory and in which IL-11 is produced in a lung-specific fashion $(50,51)$. In the CC10-IL-11 mice, the Clara cell $10 \mathrm{kDa}$ (CC10) protein promoter was used to overexpress IL-11 in a constitutive fashion. In the CC10-rtTA-IL-11 mice, IL-11 was produced in the lung in an externally regulatable fashion. In this mouse, regulation is accomplished using 2 transgenic constructs. The first construct, CC10-rtTA-hGH, contains the CC10 promoter, the reverse tetracycline transactivator ( $\mathrm{rtTA}$ ), and human growth hormone (hGH) intronic and polyadenylation sequences. The second construct, tet-O-CMV-IL-11-hGH, contains a polymeric tetracycline operator (tet-O), minimal CMV promoter, human IL-11 cDNA, and hGH. These animals have very low to undetectable levels of IL-11 in their lungs at base line and nanogram-per-milliliter quantities after transgene induction by addition of doxycycline to the animal's drinking water (see below). When CC10-IL-11 mice were being evaluated, $\operatorname{Tg}(-)$ littermate animals were used as controls. When dual-construct-positive CC10-rtTA-IL-11 mice $[\mathrm{Tg}(+)$ mice] were being evaluated, $\mathrm{Tg}(-)$ mice on normal or doxycycline water were used as experimental controls. Both kinds of IL-11 transgenic mouse had been bred for over 10 generations onto a C57BL/6 background. The methods that were used to generate, genotype, and characterize these mice in room air and $100 \% \mathrm{O}_{2}$ have been described $(6,50,51)$.

A1(-/-) null mutant mice. A1a-null mutant (-/-) mice were generated as previously described by our laboratory (52). In these mice, a 4-kb DNA fragment from exon 1 of the A1a gene was deleted and replaced with a PGK-neo-poly(A) cassette. The genotypes of newborn mice were defined by PCR using tail biopsy-derived DNA from 4- to 8-week-old animals with 2 modified primer pairs. The oligonucleotide primers 5'-CAGGGAAGATGGCTGAGTCT-3' and $5^{\prime}$-TTCTGCCGTATCCATTCTCC- $3^{\prime}$ were used for detection of the endogenous gene, and primers 5 '-CATCATAGTTTGTCATTCAGGAAG-3' 
Table 1

Primer pairs used for RT-PCR

\begin{tabular}{|c|c|}
\hline Gene name & Primers \\
\hline \multirow[t]{2}{*}{ Bad } & Upper: 5'-TGCAGAGGATGATTGCTGAC-3' \\
\hline & Lower: 5'-GATCAGCTCGGGCACTTTAG-3' \\
\hline \multirow[t]{2}{*}{$\mathrm{Bcl}-2$} & Upper: 5'-CTGGCATCTTCTCCTTCCAG-3' \\
\hline & Lower: 5'-GACGGTAGCGACGAGAGAAG-3' \\
\hline \multirow[t]{2}{*}{ Fas } & Upper: 5'-ATGCACACTCTGCGATGAAG-3' \\
\hline & Lower: 5'-TTCAGGGTCATCCTGTCTCC-3' \\
\hline \multirow[t]{2}{*}{ FasL } & Upper: 5'-CATCACAACCACTCCСACTG-3' \\
\hline & Lower: 5'-GTTCTGCCAGTTCCTTCTGC-3' \\
\hline \multirow[t]{2}{*}{ TRAIL } & Upper: 5'-CTTCCGATTTCAGGAAGCTG-3' \\
\hline & Lower: 5'-GTTCCAGCTGCCTTTCTGTC-3' \\
\hline \multirow[t]{2}{*}{ Caspase-3 } & Upper: 5'-AGTCTGACTGGAAAGCCGAA-3' \\
\hline & Lower: 5'-AAATTCTAGCTTGTGCGCGT-3' \\
\hline \multirow[t]{2}{*}{ Caspase-6 } & Upper: 5'-TTCAGACGTTGACTGGCTTG-3' \\
\hline & Lower: 5'-TTTCTGTTCACCAGCGTCAG-3' \\
\hline \multirow[t]{2}{*}{ Caspase-8 } & Upper: 5'-GCTGGAAGATGACTTGAGCC-3' \\
\hline & Lower: 5'-CGTTCCATAGACGACACCCT-3' \\
\hline \multirow[t]{2}{*}{ Caspase-9 } & Upper: 5'-CCTGCTTAGAGGACACAGGC-3' \\
\hline & Lower: 5'-TGGTCTGAGAACCTCTGGCT-3' \\
\hline \multirow[t]{2}{*}{ PKC } & Upper: 5'-TACCGGGCTACGTTTTATGC-3' \\
\hline & Lower: 5'-CCAGGAGGGACCAGTTGATA-3' \\
\hline \multirow[t]{2}{*}{ Bak } & Upper: 5'-CCAACATTGCATGGTGCTAC-3' \\
\hline & Lower: 5'-AGGAGTGTTGGGAACACAGG-3' \\
\hline \multirow[t]{2}{*}{ Bax } & Upper: 5'-CTGCAGAGGATGATTGCTGA-3' \\
\hline & Lower: 5'-GAGGAAGTCCAGTGTCCAGC-3' \\
\hline \multirow[t]{2}{*}{ Bid } & Upper: 5'-TCCACAACATTGCCAGACTA-3' \\
\hline & Lower: 5'-CACTCAAGCTGAACGCAGAG-3' \\
\hline \multirow[t]{2}{*}{ Bim } & Upper: 5'-GCCAAGCAACCTTCTGATGT-3' \\
\hline & Lower: 5'-CATTTGCAAACACССТССТT-3' \\
\hline \multirow[t]{2}{*}{ AIF } & Upper: 5'-CAGCTGTTCCCTGAGAAAGG-3' \\
\hline & Lower: 5'-CTCCAGCCAGTCTTCCACTC-3' \\
\hline \multirow[t]{2}{*}{$\beta$-Actin } & Upper: 5'-GTGGGCCGCTCTAGGCACCA-3' \\
\hline & Lower: 5'-TGGCCTTAGGGTTCAGGGGG-3' \\
\hline \multirow[t]{2}{*}{ Bcl-xl } & Upper: 5'-TTCGGGATGGAGTAAACTGG-3' \\
\hline & Lower: 5'-TGGATCCAAGGCTCTAGGTG-3' \\
\hline
\end{tabular}

and 5'-GGGTGGGGTGGGATTAGATAAATG-3' were used for detection of knockouts. Although these mice have a null mutation of $A 1 a$, they have approximately $90 \%$ decreases in the expression of A1b and A1d as well (52).

VEGF transgenic mice. CC10-rtTA-VEGF transgenic mice were generated in our laboratory to overexpress VEGF 165 in an inducible manner in the murine lung. The construct CC10-rtTA-hGH was generated as described above. The second construct, tet-O-CMV-VEGF-hGH, was prepared by replacement of the IL-11 cDNA in the construct tet-O-CMV-IL-11-hGH, as described above, with human VEGF 165. The methods that were used to generate, genotype, and characterize these mice in room air and $100 \% \mathrm{O}_{2}$ have been described (53).

Breeding of transgenic and null mutant mice. CC10-IL-11, CC10-rtTA-IL-11, and CC10-rtTA-VEGF mice with WT and null (-/-) A1 loci were generated by breeding of parental mice (with $[+/+] A 1$ loci) with $A 1 a(-/-)$ mates as previously described by our laboratory (53). The phenotypes of A1(+/+), $\mathrm{A} 1(-/-), \mathrm{Tg}(+) / \mathrm{A} 1(+/+)$, and $\mathrm{Tg}(+) / \mathrm{A} 1(-/-)$ progeny were compared. PCR was used to genotype all offspring, using primers that detected rtTA, the junction region of the IL-11 or VEGF-hGH construct and A1a. All of the parental and progeny mice were on a C57BL/6 genetic background.

Administration of doxycycline water. CC10-rtTA-IL-11 and CC10-rtTAVEGF animals were maintained on normal water until 4-6 weeks of age. At that time they were randomized to receive normal water or water containing doxycycline $(0.5 \mathrm{mg} / \mathrm{ml})$ as described previously $(51,54)$.
Murine 100\% $\mathrm{O}_{2}$ exposure. Adult 6- to 8-week-old $\mathrm{Tg}(-)$ and $\mathrm{Tg}(+)$ mice with WT or null mutant $A 1$ loci were exposed to room air (controls) or continuously to $100 \% \mathrm{O}_{2}$ in a Plexiglas chamber as previously described $(5,6)$. In many experiments survival was the evaluation end point. In others the animals were sacrificed at selected time points and lungs were obtained for BAL, TUNEL, mRNA, and/or Western blot evaluations. All protocols were reviewed and approved by the Institutional Animal Care and Use Committee at Yale University School of Medicine.

$B A L$ and protein quantification. Mice were euthanized, the trachea was isolated by blunt dissection, and small-caliber tubing was inserted and secured in the airway. Two volumes of $1.0 \mathrm{ml}$ of PBS were then instilled and gently aspirated and pooled. Each BAL sample was centrifuged, and the supernatants were stored at $-70^{\circ} \mathrm{C}$ until used. BAL protein was assayed as an index of lung injury and capillary protein leak. Protein quantification was accomplished with a DC assay kit (Bio-Rad Inc.).

$m R N A$ analysis. mRNA levels were assessed using RT-PCR and Northern blot analysis as described previously by our laboratory (54). Ribonuclease protection assays (RPAs) were also used. In these experiments, total cellular RNA from lungs or a variety of other mouse tissues or from cells in culture was obtained using TRIzol reagent (Invitrogen Corp.) according to the manufacturer's instructions. The RPAs were performed with RiboQuant kits (BD Biosciences - Pharmingen) according to the manufacturer's instructions. In the RT-PCR assays, equal amounts $(1 \mu \mathrm{g})$ of RNA from each experimental condition were reverse-transcribed, and gene-specific primers were used to amplify selected regions of the target moiety. The primers that were used are described in Table 1. $\beta$-Actin was used as an internal and loading control. Amplified PCR products were detected using ethidium bromide gel electrophoresis, sequenced, and quantitated electronically.

In selected experiments, real-time RT-PCR was used. These evaluations were performed using a QuantiTect SYBR Green RT-PCR kit (QIAGEN Inc.) according to the instructions provided by the manufacturer. In these evaluations, reactions were made by combination of $12.5 \mu$ l of SYBR RTPCR Master Mix (QIAGEN Inc.), $0.25 \mu$ l of QuantiTect RT Mix (QIAGEN Inc.), $1 \mu \mathrm{l}$ of upstream primer, $1 \mu \mathrm{l}$ of downstream primer, $8.25 \mu \mathrm{l}$ of RNasefree water, and $2 \mu \mathrm{l}(100 \mathrm{ng} / \mu \mathrm{l})$ of RNA template. RNA template concentrations $(1 \mu \mathrm{g} / \mu \mathrm{l}, 500 \mathrm{ng} / \mu \mathrm{l}, 250 \mathrm{ng} / \mu \mathrm{l}, 125 \mathrm{ng} / \mu \mathrm{l}, 65 \mathrm{ng} / \mu \mathrm{l}$, and $32 \mathrm{ng} / \mu \mathrm{l})$ were used to generate a standard curve. A negative control containing no RNA template was introduced in each run. Mouse $\beta$-actin gene was amplified as an internal control. The RT-PCR was performed using DNA Engine Opticon 2 (MJ Research Inc.), in which the mixture was heated to $50^{\circ} \mathrm{C}$ for 30 minutes for reverse transcription, heated to $95^{\circ} \mathrm{C}$ for 5 minutes, and then cycled 35 times at $94^{\circ} \mathrm{C}$ for 30 seconds, $60^{\circ} \mathrm{C}$ for 1 minute, and $72^{\circ} \mathrm{C}$ for 1 minute. To verify the specificity of the amplification reaction, melting-curve analysis was performed. The threshold cycle $\left(C_{\mathrm{T}}\right)$ value is taken as the fractional cycle number at which the emitted fluorescence of the sample passes a fixed threshold above the baseline. Relative quantification was calculated using the standard curve to obtain the mRNA concentration. The ratio of the target and $\beta$-actin mRNA was used to compare gene expression in different murine groups. All the amplification reactions were run in triplicate in a minimum of 2 independent assays.

TUNEL assay. End labeling of exposed 3'-OH ends of DNA fragments in paraffin-embedded tissue was undertaken with the TUNEL AP In Situ Cell Death Detection Kit (Roche Diagnostics Corp.) using the instructions provided by the manufacturer. After staining, 20 fields of alveoli were randomly chosen, and 2,000 nuclei were counted per lung. The labeled cells were expressed as a percentage of total nuclei.

Protein extraction and Western blot analysis. Whole-lung and cell-monolayer lysates were evaluated by Western blot. Lung lysates were prepared using lysis buffer as previously described (54). The cell monolayers were washed 
twice with ice-cold PBS containing $1 \mathrm{mM}$ sodium orthovanadate and 1 $\mathrm{mM}$ sodium fluoride, and lysed with lysis buffer (15 mM HEPES [pH 7.9], $10 \%$ glycerol, $0.5 \%$ NP-40, $250 \mathrm{mM} \mathrm{NaCl}, 0.1 \mathrm{mM}$ EDTA, $1 \mathrm{mM}$ sodium orthovanadate, $10 \mathrm{mM}$ sodium fluoride, $10 \mathrm{mM}$ DTT, and 1 tablet of Complete Mini Protease Inhibitor Cocktail [Roche Diagnostics Corp.] per $10 \mathrm{ml}$ lysis buffer). The lysates were then clarified by centrifugation at $10,000 \mathrm{~g}$ for 15 minutes, and supernatant protein concentrations were determined with a Bio-Rad DC assay kit. The samples were then mixed with an equal volume of $2 \times$ SDS-PAGE sample buffer (100 mM Tris-Cl [pH 6.8], $200 \mathrm{mM}$ DTT, $4 \%$ SDS, $0.2 \%$ bromphenol blue, $20 \%$ glycerol) and heated in a boiling water bath, and equal amounts were loaded onto $12 \%$ or $15 \%$ SDS-polyacrylamide gels (Bio-Rad) and transferred to Immun-Blot PVDF membranes (Bio-Rad). After transfer, the membranes were blocked for 1 hour in nonfat dried milk, rinsed, incubated with the appropriate primary antibodies for 1.5 hours at room temperature or overnight at $4{ }^{\circ} \mathrm{C}$, washed, incubated with secondary antibody (diluted 1:1,000-1:2,000) for 1.5 hours at room temperature, and washed in Tris-buffered saline ( $\mathrm{pH} 7.4$ ) containing $0.1 \%$ Tween- 20 . Immunoreactive proteins were visualized using the $20 \times$ LumiGLO reagent and $20 \times$ Peroxide according to the manufacturer's instructions (Cell Signaling Technology Inc.). The membranes were exposed to BioMax MR films (Eastman Kodak Co.). Rabbit or goat polyclonal antibodies reactive to A1, Bcl-2, caspase-3, caspase-9, $\beta$-tubulin, and tBid were purchased from Santa Cruz Biotechnology Inc., and polyclonal anti-caspase- 8 was from BD Biosciences. The anti-Fas antibody was from Upstate Group Inc. The antiBax, anti-Bcl-xl, and anti-Bad antibodies were obtained from Cell Signaling Technology Inc. The anti-Bak and anti-FasL antibodies were obtained from Oncogene Research Products.

Assessments of caspase activity. The bioactivities of caspase- $3,-8$, and -9 were measured with colorimetric assays using the CaspACE Assay System (Promega Corp.), Caspase-8 Colorimetric Activity assay kit (Chemicon International Inc.), and Caspase 9 Activity Assay kit (Calbiochem Immunochemicals Inc.), respectively. In brief, lung tissues were homogenized and MLE12 cells were resuspended in lysis buffer. They were then centrifuged, and the supernatants were incubated with the colorimetric substrate Ac-Asp-Glu-Val-Asp-p-nitroanilide (Ac-DEVD-pNA), $N$-acetyl-Ile-Glu-ThrAsp- $p$-nitroanilide (Ac-IETD- $p$ NA), or Ac-Leu-Glu-His-Asp- $p$-nitroanilide (Ac-LEHD- $p$ NA) for caspases-3, -8 , and -9, respectively. The release of $p$-nitroanilide from Ac-DEVD-pNA, Ac-IETD- $p$ NA, or Ac-LEHD-pNA was measured at $405 \mathrm{~nm}$ using a spectrophotometer.

In vitro cell culture and hyperoxia and $\mathrm{H}_{2} \mathrm{O}_{2}$ exposures. Transformed murine lung epithelial cells (MLE12; American Type Culture Collection) were a generous gift from Patty J. Lee (Yale University, New Haven, Connecticut, USA). They were grown to confluence in DMEM (Invitrogen Corp.) supplemented with $2 \%$ FBS and 10\% penicillin-streptomycin (Invitrogen Corp.) in a humidified atmosphere in $5 \% \mathrm{CO}_{2}$ and air. Hyperoxic conditions were achieved by placement of confluent cells in $95 \% \mathrm{O}_{2} / 5 \% \mathrm{CO}_{2}$ at $37^{\circ} \mathrm{C}$ in a tightly sealed modular chamber (Billup-Rothberg Inc.) for up to 72 hours. The effects of rIL-11 were evaluated by incubation of the cells in the presence or absence of murine rIL-11 (R\&D Systems Inc.).

Annexin V-propidium iodide evaluation. MLE12 cell annexin V and propidium iodide staining were undertaken with the Annexin V-FITC apoptosis detection kit (BD Biosciences) as described by the manufacturer. Analysis was undertaken by flow cytometry (BD).

Plasmid constructs and transient transfection. A1a and A1d cDNA was amplified using PCR with the following primers: A1a, upper, 5'-CACGGACTA GTGGATCC(BamHI)GATGGCTGAGTCTGAGCTC-3'; A1a, lower, 5'-G TGCTCTAGCAAGCT(HindII)TTGGAGAAAGAGCATTTCCCA-3'; A1d, upper, 5'-GGTGGGCAGCAGGATCCAGCACTGCCAGGGAAGATG-3'; and A1d, lower, 5'-TCTCTCTGGTCCGAAGCTTTCCTTGAGGAGAAAGAGCAT-3'. Both genes were amplified from mouse lung Quick-Clone cDNA (BD Biosciences - Clontech) and were cloned into the pcDNA3.1 vector (Invitrogen Corp.). MLE12 cells were incubated for 6 hours with vector DNA mixtures that did not contain (pcDNA3.1) or contained A1a (A1a-pcDNA3.1) or A1d (A1d-pcDNA3.1) inserts. After incubation, the cells were washed and incubated for an additional 16 hours in complete medium. The cells were then passed, and stable cell lines were selected by addition of $\mathrm{G} 418$ to the medium. The responses of these cells to hyperoxia and $\mathrm{H}_{2} \mathrm{O}_{2}$ were evaluated as noted above.

Statistics. Normally distributed data are expressed as mean \pm SEM and were assessed for significance by Student's $t$ test or ANOVA as appropriate. Data that were not normally distributed were assessed for significance using the Wilcoxon rank sum test. Survival studies were evaluated using log-rank analysis (55). Statistical analysis was performed using Stata (version 7.0; StataCorp LP), DeltaGraph (RockWare Inc.), and GraphPad Prism 3.0 (GraphPad Software Inc.) software. Statistical significance was defined at a level of $P$ less than 0.05 .

\section{Acknowledgments}

The authors wish to thank Kathleen Bertier for her excellent secretarial and administrative assistance, and the donors of the reagents that were employed. This work was supported by NIH grants 5P01HL56389-08, R01HL064242-05, 1R01HL078744-01, and AR46032 (to J.A. Elias).

Received for publication August 11, 2004, and accepted in revised form January 4, 2005.

Address correspondence to: Jack Elias, Department of Internal Medicine, Section of Pulmonary and Critical Care Medicine, Yale University School of Medicine, 300 Cedar Street, S441 TAC, New Haven, Connecticut 06520-8057, USA. Phone: (203) 785-4163; Fax: (203) 785-3826; E-mail: jack.elias@yale.edu.
1. Crapo, J.D. 1986. Morphologic changes in pulmonary oxygen toxicity. Annu. Rev. Physiol. 48:721-731.

2. Barazzone, C., Horowitz, S., Donati, Y.R., Rodriguez, I., and Piguet, P.F. 1998. Oxygen toxicity in mouse lung: pathways to cell death. Am. J. Respir. Cell Mol. Biol. 19:573-581.

3. Barazzone, C., and White, C.W. 2000. Mechanisms of cell injury and death in hypoxia: role of cytokines and Bcl-2 family proteins. Am. J. Respir. Cell Mol. Biol. 22:517-519.

4. O'Reilly, M.A., et al. 2000. Bcl-2 family gene expression during severe hyperoxia induced lung injury. Lab. Invest. 80:1845-1854.

5. Ward, N.S., et al. 2000. Interleukin-6-induced protection in hyperoxic acute lung injury. Am. J. Respir. Cell Mol. Biol. 22:535-542.

6. Waxman, A.B., et al. 1998. Targeted lung expres- sion of interleukin-11 enhances murine tolerance of $100 \%$ oxygen and diminishes hyperoxia-induced DNA fragmentation. J. Clin. Invest. 101:1970-1982.

7. Freeman, B.A., and Crapo, J.D. 1982. Biology of disease: free radicals and tissue injury. Lab. Invest. 47:412-426.

8. Mantell, L.L., Horowitz, S., Davis, J.M., and Kazzaz, J.A. 1999. Hyperoxia-induced cell death in the lung: the correlation of apoptosis, necrosis, and inflammation. Ann. N. Y. Acad. Sci. 887:171-180.

9. White, C.W., et al. 1987. Recombinant tumor necrosis factor/cachectin and interleukin 1 pretreatment decreases lung oxidized gluthathione accumulation, lung injury, and mortality in rats exposed to hyperoxia. J. Clin. Invest. 79:1868-1873.

10. Tsan, M.F., White, J.E., Santana, T.A., and Lee, C.Y. 1990. Tracheal insufflation of tumor necrosis fac- tor protects rats against oxygen toxicity. J. Appl. Physiol. 68:1211-1219.

11. Gardner, P.R., Nguyen, D.D., and White, C.W. 1994. Aconitase is a sensitive and critical target of oxygen poisoning in cultured mammalian cells and in rat lungs. Proc. Natl. Acad. Sci. U. S. A. 91:12248-12252.

12. Gardner, P.R., Raineri, I., Epstein, L.B., and White, C.W. 1995. Superoxide radical and iron modulate aconitase activity in mammalian cells. J. Biol. Chem. 270:13399-13405.

13. Joza, N., Kroemer, G., and Penninger, J.M. 2002. Genetic analysis of the mammalian cell death machinery. Trends Genet. 18:142-149.

14. Werner, A.B., de Vries, E., Tait, S.W., Bontjer, I., and Borst, J. 2002. Bcl-2 family member Bfl-1/A1 sequesters truncated bid to inhibit its collaboration with pro-apoptotic Bak or Bax. J. Biol. Chem. 
277:22781-22788.

15. Wang, X., et al. 2003. Necrotic cell death in response to oxidant stress involves the activation of the apoptogenic caspase-8/bid pathway. J. Biol. Chem. 278:29184-29191.

16. Perkowski, S., et al. 2003. Gene expression profiling of the early pulmonary response to hyperoxia in mice. Am. J. Respir. Cell Mol. Biol. 28:682-696.

17. Xiang, Z., et al. 2001. Essential role of the prosurvival bcl-2 homologue A1 in mast cell survival after allergic activation. J. Exp. Med. 194:1561-1569.

18. Sakuma, H., et al. 2002. High glucose inhibits apoptosis in human coronary artery smooth muscle cells by increasing bcl-xL and bfl-1/A1. Am. J. Physiol. Cell Physiol. 283:C422-C428.

19. Gonzalez, J., Orlofsky, A., and Prystowsky, M.B. 2003. A1 is a growth-permissive antiapoptotic fac tor mediating postactivation survival in T cells. Blood. 101:2679-2685.

20. Schoemaker, M.H., et al. 2003. Resistance of rat hepatocytes against bile acid-induced apoptosis in cholestatic liver injury is due to nuclear factorkappa B activation. J. Hepatol. 39:153-161.

21. Mitsiades, C.S., et al. 2002. Activation of NFkappaB and upregulation of intracellular antiapoptotic proteins via the IGF-1/Akt signaling in human multiple myeloma cells: therapeutic implications. Oncogene. 21:5673-5683.

22. Liu, W.L., Guo, X., Chen, Q.Q., and Guo, Z.G. 2002. VEGF protects bovine aortic endothelial cells from TNF-alpha- and $\mathrm{H} 2 \mathrm{O} 2$-induced apoptosis via comodulatory effects on p38- and p42/p44-CCDPK signaling. Acta Pharmacol. Sin. 23:45-49.

23. D'Sa-Eipper, C., and Chinnadurai, G. 1998. Functional dissection of Bfl-1, a Bcl-2 homolog: antiapoptosis, oncogene-cooperation and cell proliferation activities. Oncogene. 16:3105-3114.

24. D'Sa-Eipper, C., Subramanian, T., and Chinnadurai, G. 1996. bfl-1, a bcl-2 homologue, suppresses p53 induced apoptosis and exhibits potent cooperative transforming activity. Cancer Res. 56:3879-3882.

25. Duriez, P.J., Wong, F., Dorovini-Zis, K., Shahidi, R., and Karsan, A. 2000. A1 functions at the mitochondria to delay endothelial apoptosis in response to tumor necrosis factor. J. Biol. Chem. 275:18099-18107.

26. Zong, W.X., Edelstein, L.C., Chen, C., Bash, J., and Gelinas, C. 1999. The prosurvival Bcl-2 homolog Bfl-1/A1 is a direct transcriptional target of NFkappaB that blocks TNFalpha-induced apoptosis. Genes Dev. 13:382-387.

27. Karsan, A., Yee, E., and Harlan, J.M. 1996. Endothelial cell death induced by tumor necrosis factor-alpha is inhibited by the Bcl-2 family member, A1. J. Biol. Chem. 271:27201-27204.
28. Corne, J., et al. 2000. IL-13 stimulates vascular endothelial cell growth factor and protects against hyperoxic acute lung injury. J. Clin. Invest. 106:783-791.

29. Tateda, K., et al. 2003. Hyperoxia mediates acute lung injury and increased lethality in murine Legionella pneumonia: the role of apoptosis. J. Immunol. 170:4209-4216.

30. Paine, R., 3rd, et al. 2003. Transgenic overexpression of granulocyte macrophage-colony stimulating factor in the lung prevents hyperoxic lung injury. Am. J. Pathol. 163:2397-2406.

31. Budinger, G.R., et al. 2002. Hyperoxia-induced apoptosis does not require mitochondrial reactive oxygen species and is regulated by $\mathrm{Bcl}-2$ proteins. J. Biol. Chem. 277:15654-15660.

32. Ko, J.K., et al. 2003. Bfl-1S, a novel alternative splice variant of Bfl-1, localizes in the nucleus via its C-terminus and prevents cell death. Oncogene. 22:2457-2465

33. Einarsson, O., Geba, G.P., Zhu, Z., Landry, M., and Elias, J.A. 1996. Interleukin-11: stimulation in vivo and in vitro by respiratory viruses and induction of airways hyperresponsiveness. J. Clin. Invest. 97:915-924.

34. Zheng, T., Zhu, Z., Wang, J., Homer, R.J., and Elias, J.A. 2001. IL-11: insights in asthma from overexpression transgenic modeling. J. Allergy Clin. Immunol. 108:489-496.

35. Trepicchio, W.L., Wang, L., Bozza, M., and Dorner, A.J. 1997. IL-11 regulates macrophage effector function through the inhibition of nuclear factorkappaB. J. Immunol. 159:5661-5670.

36. Trepicchio, W.L., et al. 1999. Interleukin-11 therapy selectively downregulates type I cytokine proinflammatory pathways in psoriasis lesions. J. Clin. Invest. 104:1527-1537.

37. Trepicchio, W.L., and Dorner, A.J. 1998. Interleukin-11. A gp130 cytokine. Ann. N. Y. Acad. Sci. 856:12-21.

38. Trepicchio, W.L., Bozza, M., Pedneault, G., and Dorner, A.J. 1996. Recombinant human IL-11 attenuates the inflammatory response through down-regulation of proinflammatory cytokine release and nitric oxide production. J. Immunol. 157:3627-3634

39. Leng, S.X., and Elias, J.A. 1997. Interleukin-11 inhibits macrophage interleukin-12 production. J. Immunol. 159:2161-2168.

40. Kasahara, Y., et al. 2000. Inhibition of VEGF receptors causes lung cell apoptosis and emphysema. J. Clin. Invest. 106:1311-1319.

41. Pidgeon, G.P., Barr, M.P., Harmey, J.H., Foley, D.A., and Bouchier-Hayes, D.J. 2001. Vascular endothelial growth factor (VEGF) upregulates
BCL-2 and inhibits apoptosis in human and murine mammary adenocarcinoma cells. $\mathrm{Br}$. J. Cancer. 85:273-278

42. Beierle, E.A., Strande, L.F., and Chen, M.K. 2002. VEGF upregulates Bcl-2 expression and is associated with decreased apoptosis in neuroblastoma cells. J. Pediatr. Surg. 37:467-471.

43. Lin, E.Y., Orlofsky, A., Berger, M.S., and Prystowsky, M.B. 1993. Characterization of A1, a novel hemopoietic-specific early-response gene with sequence similarity to bcl-2. J. Immunol. 151:1979-1988.

44. Schuchmann, M., and Galle, P.R. 2001. Apoptosis in liver disease. Eur. J. Gastroenterol. Hepatol. 13:785-790.

45. Eugenin, E.A., D’Aversa, T.G., Lopez, L., Calderon, T.M., and Berman, J.W. 2003. MCP-1 (CCL2) protects human neurons and astrocytes from NMDA or HIV-tat-induced apoptosis. J. Neurochem. 85:1299-1311.

46. Moriishi, K., Koura, M., and Matsuura, Y. 2002. Induction of Bad-mediated apoptosis by Sindbis virus infection: involvement of pro-survival members of the Bcl-2 family. Virology. 292:258-271.

47. Rahman, I. 2003. Oxidative stress, chromatin remodeling and gene transcription in inflammation and chronic lung diseases. J. Biochem. Mol. Biol. 36:95-109.

48. Andreadis, A.A., Hazen, S.L., Comhair, S.A., and Erzurum, S.C. 2003. Oxidative and nitrosative events in asthma. Free Radic. Biol. Med. 35:213-225.

49. Tuder, R.M., et al. 2003. Oxidative stress and apoptosis interact and cause emphysema due to vascular endothelial growth factor receptor blockade. Am.J. Respir. Cell Mol. Biol. 29:88-97.

50. Tang, W., et al. 1996. Targeted expression of IL-11 in the murine airway causes lymphocytic inflammation, bronchial remodeling, and airways obstruction. J. Clin. Invest. 98:2845-2853.

51. Ray, P., et al. 1997. Regulated overexpression of interleukin 11 in the lung. Use to dissociate development-dependent and -independent phenotypes. J. Clin. Invest. 100:2501-2511.

52. Hamasaki, A., et al. 1998. Accelerated neutrophil apoptosis in mice lacking A1-a, a subtype of the bcl-2-related A1 gene. J. Exp. Med. 188:1985-1992.

53. Lee, C.G., et al. 2004. Vascular endothelial growth factor (VEGF) induces remodeling and enhances Th2 sensitization and inflammation in the lung. Nat. Med. 10:1095-1103.

54. Zheng, T., et al. 2000. Inducible targeting of IL-13 to the adult lung causes matrix metalloproteinase- and cathepsin-dependent emphysema. J. Clin. Invest. 106:1081-1093.

55. Mantel, N. 1966. Evaluation of survival data and two new rank order statistics arising in its consideration. Cancer Chemother. Rep. 50:163-170. 